\title{
Linacs for Medical Isotope Production
}

\author{
A. Pramudita* \\ Center for Accelerator Technology and Material Process, National Nuclear Energy Agency \\ Jl. Babarsari, Yogyakarta 55281, Indonesia
}

\section{ARTICLE INFO}

Article history:

Received 01 February 2010

Received in Revised form 05 April 2011

Accepted 20 April 2011

Keywords:

Electron linacs

Proton linacs

Photonuclear

Photofission

Medical radioisotopes

\begin{abstract}
A B S T R A C T
This paper reviews efforts on using high energy (25-30 MeV) and high power $(10-20 \mathrm{~kW})$ electron linacs and lower energy $(7 \mathrm{MeV})$ proton linacs for medical radioisotope production. Using high energy x-rays from the electron linacs, PET (Positron Emission Tomography) radioisotopes are produced through photonuclear reactions such as ${ }^{19} \mathrm{~F}(\gamma, \mathrm{n}){ }^{18} \mathrm{~F}$, which also allow production of other PET radionuclides ${ }^{11} \mathrm{C},{ }^{13} \mathrm{~N}$, and ${ }^{15} \mathrm{O}$. Other mostly used medical radionuclides ${ }^{99 \mathrm{~m}} \mathrm{Tc}$ can also be obtained by using the electron linacs, through photofission or photonuclear reactions. Proton linacs for PET have also been recently developed and the product has been available in the market since 2005. The linacs have been tested for ${ }^{18} \mathrm{~F}$ production. As a proton accelerator, the target systems and nuclear reactions are similar to the ones used in PET cyclotrons.
\end{abstract}

(C) 2011 Atom Indonesia. All rights reserved

\section{INTRODUCTION}

In the medical world, linear accelerators (linacs) particularly electron linacs, are mostly used to generate high energy electron beam to be used directly or converted to high energy photon for gamma therapy, mostly for cancer treatment. Medical isotope production for diagnostics such as ${ }^{99 \mathrm{~m}} \mathrm{Tc}$ is carried out by neutron irradiation in nuclear reactors, or in the case of short-lived isotopes such as ${ }^{18} \mathrm{~F}$ for PET (Positron Emission Tomography) by using cyclotrons.

However some studies on using high energy (25-30 MeV) and high power (10-20 kW) electron linacs for medical isotope production through photonuclear reactions such as ${ }^{19} \mathrm{~F}(\gamma, \mathrm{n}){ }^{18} \mathrm{~F}$, which can use ${ }^{19} \mathrm{~F}$ of natural $(100 \%)$ abundance as target, had been carried out. This is in contrast with ${ }^{18} \mathrm{O}(\mathrm{p}, \mathrm{n}){ }^{18} \mathrm{~F}$ of proton reactions which require expensive gas targets enriched with isotopes ${ }^{18} \mathrm{O}$ in production using cyclotrons. Similar photonuclear reactions also allow production of other PET radionuclides ${ }^{11} \mathrm{C},{ }^{13} \mathrm{~N}$, and ${ }^{15} \mathrm{O}$. Other medical radionuclides such as ${ }^{99 \mathrm{~m}} \mathrm{Tc}$ can also be obtained on electron accelerators, which cannot be obtained by using cyclotrons. Due to this reason the use of electron linacs is not only for gamma therapy, but also as a tool of production of radionuclides for diagnostics [1].

Ion linacs for PET has also been recently developed by Hitachi, Ltd. and AccSys Technology,

\footnotetext{
* Corresponding author.

E-mail address: pramudita@batan.go.id
}

Inc. (Hitachi's subsidiary company) and the product has been available in the market since 2005. The AccSys PULSAR-7 is a radiofrequency linear proton $\left(\mathrm{H}^{+}\right)$accelerator for PET radionuclide production consisting of $30 \mathrm{keV}$ duoplasmatron ion source, 3.5 MeV RFQ (radiofrequency quadrupole) first stage accelerator, $7 \mathrm{MeV}$ DTL (drift tube linac) second stage accelerator, shielded PET radionuclide target system, and PC-based control system [2]. The accelerator, with the beam transport line, is approximately $6.1 \mathrm{~m}$ long, weighs approximately 3 tons and the target system shield weighs approximately 9 tons. All of these units are mounted in a medical coaches $16 \mathrm{~m}$ semi-trailer. As a proton accelerator, the target system is similar to the one in PET cyclotron. However, as a linear proton accelerator it saves the weight and complexity of cyclotron magnet (minimum weight of about 14 tons of magnet and its mechanical design for optimum focusing and relativistic correction) [3].

\section{ELECTRON LINACS}

\section{PET Radionuclides}

Photonuclear cross sections yielding PET radionuclides ${ }^{15} \mathrm{O},{ }^{13} \mathrm{~N},{ }^{11} \mathrm{C}$ from respectively natural abundant isotopes all peaks at about $25 \mathrm{MeV}$ of photon energy (Figs. 1a-c). A neutron knocked off from a stable isotope yields a proton rich or positron emitter isotope which is applicable for PET. Experiments using photons from linacs at this energy had been carried out by Mac Gregor (1957) 
[4], Lutz (1969) [5], and Dovbnya et al. (1999) [1]. The result is resumed in Table 1. The most popular PET radionuclide ${ }^{18} \mathrm{~F}$ was obtained at specific activities in the order of $10^{6} \mathrm{~Bq} / \mathrm{g}$ or $10^{2} \mu \mathrm{Ci}$ per $\mu \mathrm{A}$ of linac electron beam current by using photonuclear reactions at $25 \mathrm{MeV}$ [1]. Data on production of ${ }^{15} \mathrm{O}$ at various electron linacs are given in Table 2.

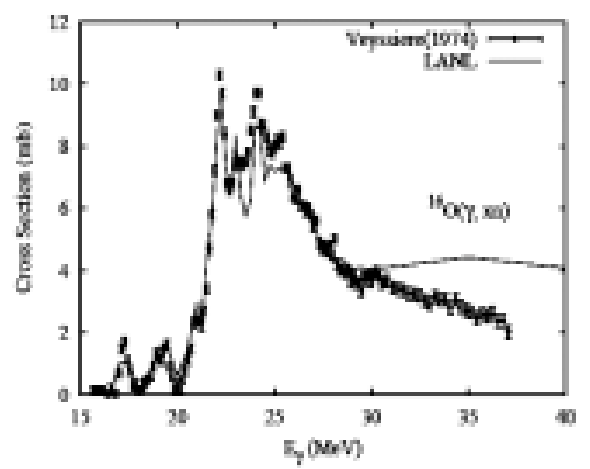

(a)

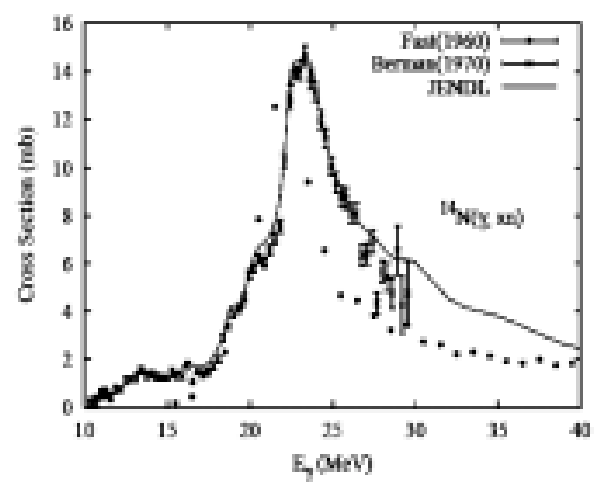

(b)

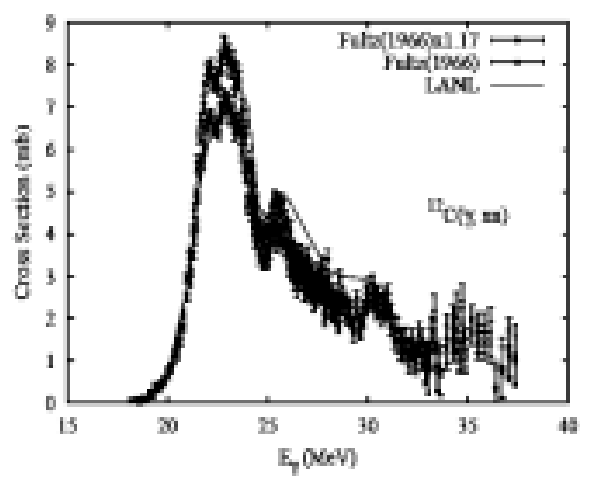

(c)

Fig. 1. Photonuclear cross sections for ${ }^{16} \mathrm{O},{ }^{14} \mathrm{~N},{ }^{12} \mathrm{C}$ yielding PET radionuclides, all peaks at about $25 \mathrm{MeV}$ of photon energy [6].
Table 1. Specific activities (in $\mathrm{Bq} / \mathrm{g}$ per $\mu \mathrm{A}$ of linac electron beam current) of some PET radionuclides obtained by using photonuclear reactions at $25 \mathrm{MeV}$ [1].

\begin{tabular}{cccc}
\hline $\begin{array}{c}\text { Radio- } \\
\text { nuclide }\end{array}$ & $\begin{array}{c}\text { Mac Gregor } \\
(\mathbf{1 9 5 7 )}\end{array}$ & $\begin{array}{c}\text { Lutz } \\
\mathbf{( 1 9 6 9 )}\end{array}$ & $\begin{array}{c}\text { Dovbnya } \text { et } \\
\text { al. }(\mathbf{1 9 9 9 )}\end{array}$ \\
\hline${ }^{11} \mathrm{C}$ & $9.25 \times 10^{6}$ & $5.30 \times 10^{6}$ & $1.90 \times 10^{6}$ \\
${ }^{13} \mathrm{~N}$ & $3.76 \times 10^{6}$ & $1.04 \times 10^{6}$ & $1.67 \times 10^{6}$ \\
${ }^{15} \mathrm{O}$ & $3.20 \times 10^{6}$ & $8.40 \times 10^{6}$ & $2.50 \times 10^{6}$ \\
${ }^{18} \mathrm{~F}$ & $2.04 \times 10^{6}$ & $2.12 \times 10^{6}$ & $1.70 \times 10^{6}$ \\
\hline
\end{tabular}

Table 2. Comparative data on production of ${ }^{15} \mathrm{O}$ at various electron linacs [1].

\begin{tabular}{cccc}
\hline Data on & $\begin{array}{c}\text { Center of } \\
\text { Nuclear } \\
\text { Medicine, } \\
\text { Cincinnati, } \\
\text { USA (1982)[7] }\end{array}$ & $\begin{array}{c}\text { Kurchatov, } \\
\text { IAE, } \\
\text { Moscow } \\
(\mathbf{1 9 8 5})[8]\end{array}$ & $\begin{array}{c}\text { NSC KIPT, } \\
\text { Kharkov } \\
(\mathbf{1 9 9 9})[1]\end{array}$ \\
\hline \multirow{2}{*}{ Irradiation } & $E_{0}=26 \mathrm{MeV}$ & $E_{0}=30 \mathrm{MeV}$ & $E_{0}=25 \mathrm{MeV}$ \\
conditions & $I_{a v}=100 \mu \mathrm{A}$ & $I_{a v}=100 \mu \mathrm{A}$ & $I_{a v}=300 \mu \mathrm{A}$ \\
& $T_{i r r}=4 \mathrm{~min}$ & $T_{i r r}=7 \mathrm{~min}$ & $T_{i r r}=10 \mathrm{~min}$ \\
Integral & $V=500 \mathrm{~cm}^{3}$ & $V=200 \mathrm{~cm}^{3}$ & $V=200 \mathrm{~cm}^{3}$ \\
activity & $184 \mathrm{mCi}$ & $700 \mathrm{mCi}$ & $130 \mathrm{mCi}$ \\
& $\left(6.8 \times 10^{9} \mathrm{~Bq}\right)$ & $\left(25.9 \times 10^{9} \mathrm{~Bq}\right)$ & $\left(4.8 \times 10^{9} \mathrm{~Bq}\right)$ \\
\hline
\end{tabular}

Target for photon irradiations is simpler in preparation as it is not subjected to direct beam heating as in the case of proton or deuteron irradiations. The beam heating is mostly borne by the heavy metal target (tungsten) converting the electron beam energy into photons at up to about $50 \%$ efficiency. Because target nuclides are composed of naturally abundant isotopes, isotopic enrichment is therefore not required. The design of the target can also take into account the high penetrability of photons.

The only drawbacks of photonuclear processes are the cross sections which are one to two orders smaller than those of nuclear reactions of proton or deuteron. Figure 1 shows cross sections in the order of millibarn, as compared to hundreds of millibarn cross sections of proton or deuteron irradiations at lower energy thresholds in Fig. 2 and Fig. 3.

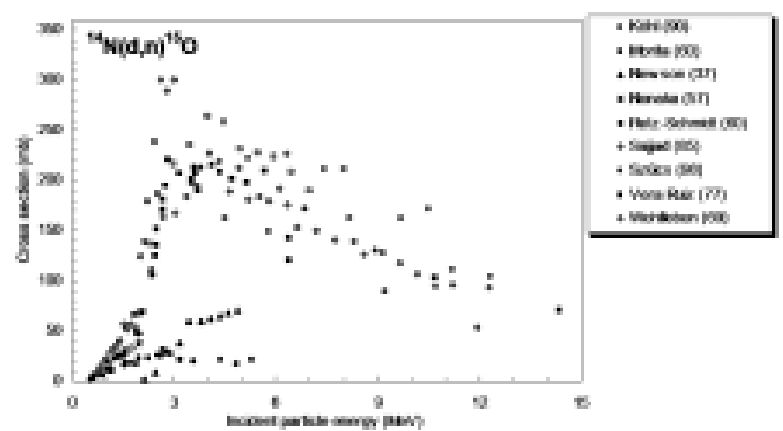

Fig. 2. Deuteron cross sections on ${ }^{14} \mathrm{~N}$ yielding PET radionuclide ${ }^{15} \mathrm{O}[9]$. 


\section{Non-PET Medical Radionuclides}

Currently it is about $80 \%$ of the yearly worldwide 40 million nuclear medicine procedures use ${ }^{99}$ Mo. The ${ }^{99}$ Mo isotope has been traditionally manufactured using nuclear reactors to irradiate highly enriched uranium targets. The Canada's National Research Universal (NRU) reactor at Chalk River, which produces about half of the world's supply, has been operating since 1957 and suffered from age-related shutdowns. The advances in accelerators enable high beam power to produce medical isotopes [10,11].

One favored approach uses photons from a high-power electron linear accelerator to produce ${ }^{99}$ Mo from natural uranium through photonuclear reaction $\gamma+{ }^{238} \mathrm{U} \rightarrow{ }^{99} \mathrm{Mo}+{ }^{13 x} \mathrm{Sn}+{ }^{2} \mathrm{D}+\ldots \ldots \ldots$. The radiochemistry to recover and refine the ${ }^{99} \mathrm{Mo}$ generated through photofission from natural uranium target is similar to which is currently in using for reactors highly enriched uranium targets. Canada's five-year plan (2010-1015) for TRIUMF includes the construction and operation of a highpower (5 MW) electron linear accelerator. A single multimegawatt machine could supply the entire Canadian market or $5-7 \%$ of the total North American market [10,12].

Another approach at Yerevan Physics Institute (YerPhI) in Armenia is to use ${ }^{100}$ Mo target through photonuclear reaction $\gamma+{ }^{100} \mathrm{Mo} \rightarrow{ }^{99} \mathrm{Mo}+\mathrm{n}$, ${ }^{99}$ Mo $\left(T_{1 / 2}=67\right.$ hours $) \rightarrow{ }^{99 \mathrm{~m}} \mathrm{Tc}\left(T_{1 / 2}=6\right.$ hours $)$, with threshold of reaction at $9.1 \mathrm{MeV}$. Unlike uranium target, this approach gives high purity isotopes and free from other radioisotopes which otherwise should be removed as wastes. The project was started at 2006 with collaborators from University of British Columbia/TRIUMF, Canada [13].

To produce ${ }^{99 \mathrm{~m}} \mathrm{Tc}$, the existing linear high current electron accelerator $(I=250 \mu \mathrm{A}$ and $E=20 \mathrm{MeV}$ ) at $\mathrm{YerPhI}$ was used to irradiate a $20 \mathrm{~g}$ target of enriched ${ }^{100}$ Mo for 100 hours to produce approximately $20-40 \mathrm{Ci}$ of ${ }^{99 \mathrm{~m}} \mathrm{Tc}$ isotope, which correspond to about $5 \mathrm{Ci}$ or $1.85 \times 10^{11} \mathrm{~Bq} /$ day. This amount would satisfy the requirements of Armenia and neighboring regional countries. Once it is successfully proven, enough radioisotopes could be provided for direct use in Armenia as well as for potential clients (according to list of IAEA).

\section{ION LINACS}

\section{PET Radionuclides}

The feasibility of using compact ion linacs for medical applications had been studied for both particle radiation therapy $[14]$ and isotope production [15]. Since 2005 Hitachi, Ltd. and AccSys Technology, Inc. (Hitachi's subsidiary company) manufactured a linear accelerator-based system for PET radiopharmaceuticals production. The system has the advantages of lower installation cost and complexity for areas where a large production center may not economically justified [2].

The AccSys PULSAR ${ }^{\circledR}-7$ is a radiofrequency linear proton $\left(\mathrm{H}^{+}\right)$accelerator system for PET radionuclide production. It consist of $\mathrm{H}^{+}$ duoplasmatron ion source $(30 \mathrm{keV})$, radiofrequency quadrupole (RFQ) as first stage accelerator (up to 3.5 MeV), drift tube linac (DTL) as second stage accelerator (up to $7 \mathrm{MeV}$ ), shielded PET radionuclide target system, and a PC-based control system. The proton energy of $7 \mathrm{MeV}$ is sufficient to produce PET radionuclide ${ }^{18} \mathrm{~F}$ (Fig. 3).

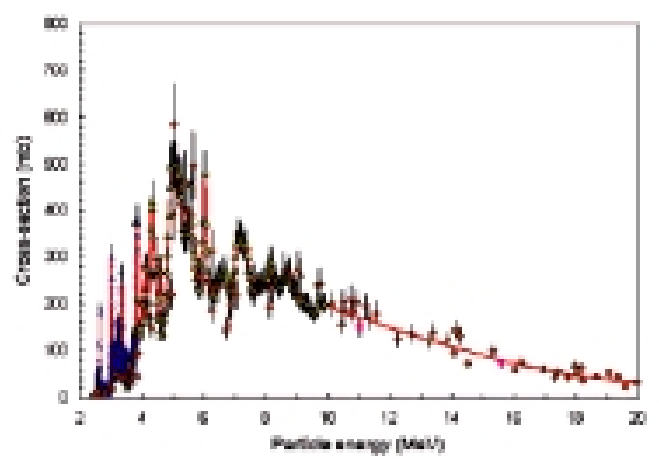

Fig. 3. Proton cross sections for ${ }^{18} \mathrm{O}(\mathrm{p}, \mathrm{n}){ }^{18} \mathrm{~F}$ yielding PET radionuclides ${ }^{18} \mathrm{~F}$.[16].

In August to September 2006 Wisconsin Medical Cyclotron (WMC) facility in West Allis, Wisconsin, tested the PULSAR ${ }^{\circledR}-7$ in a mobile configuration, mounted in a Medical Coaches $16 \mathrm{~m}$ semi-trailer (Fig. 4). The semi-trailer was located on a parking area without additional parking pad or support. On-board equipment included a radiopharmaceutical synthesis quality testing laboratory, and patient dose preparation equipment. For the evaluation tests, $\left[{ }^{18} \mathrm{~F}\right]$ FDG qualification and unit dose preparation were carried out in the WMC facility.

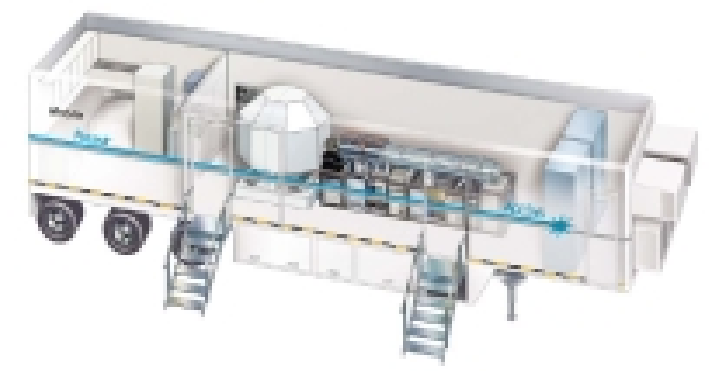

Fig. 4. AccySys $\operatorname{PULSAR}^{\circledR}-7$ in a mobile configuration, mounted in a Medical Coaches $48 \mathrm{ft}$ semi-trailer [2]. 
The drift tube linac produces a pulsed beam of $125 \mu$ s length at $85 \mathrm{~Hz}$ repetition rate at a beam current of $9 \mathrm{~mA}$ with a $1 \%$ duty cycle. The target system uses a support grid over a titanium target window to aid in cooling and support the pressurized target (about $315 \mathrm{psi}$ ). The transmission of beam through the grid is about $65 \%$. Two thin target bodies, one made of silver and one made of niobium, were evaluated each with an ${ }^{18} \mathrm{O}$ water capacity of $0.35 \mathrm{ml}$. A one hour bombardment yield $634 \mathrm{mCi}{ }^{18} \mathrm{~F}$ and a two hour $1068 \mathrm{mCi}$. This production was lower than one observed at a similar fixed (not mobile) unit, which has routinely produced over a $\mathrm{Ci} /$ hour. This was most likely caused by marginal chiller in the mobile system which restricted power to lower sustained beam current and caused interrupted bombardment. The trailer cooling system was later rebuilt by the manufacturer. The beam alignment might be also slightly offset, resulting in a beam transmission through the grid of less than $65 \%$.

The trial has demonstrated the mobile proton linac unit to achieve a $94 \%{ }^{18} \mathrm{~F}$ production batch reliability, to perform multiple daily bombardments of several hours, to produce ${ }^{18} \mathrm{~F}$ suitable for $\left[{ }^{18} \mathrm{~F}\right]$ FDG manufacture for small scale distribution, and the product met quality standard.

\section{CONCLUSIONS}

The electron and proton linear accelerators have been proven to have feasibility for medical isotope production, which at present mostly produced commercially by using cyclotrons or nuclear reactors. For the electron accelerators, however, due to lower cross sections and higher energy thresholds, further efforts are still underway to prove that it is commercially feasible. As for the proton linear accelerators, fixed and mobile compact models have been developed and commercially available, providing more choices other than compact or baby cyclotrons, which could be considered for installation.

\section{ACKNOWLEDGEMENT}

The author thanks Mr. Iyos Subki, the former Chairman of the Indonesian National Nuclear Energy Agency, for corrections and suggestions provided by him at the early stage of writing this paper.

\section{REFERENCES}

1. A.N. Dovbnya, A.S. Zadvorny and B.I. Shramenko, Production of Short-Lived Radionuclides on the Electron Linac for PET, in: Problems in Atomic Science and Technology 3 (1999) 105.

2. Anonymous, Test Results for Mobile PULSAR ${ }^{\circledR}$ System, Cyclomedical Application Group (2008).

3. Y.S. Kim, D.H. An, J.S. Chai, et al., New Design of the KIRAMS-13 Cyclotron for Regional Cyclotron Center, Proceedings of APAC 2004, Gyeongju, Korea (2004) 338.

4. M.H. McGregor, Nucleonics 15 (1957) 11.

5. G.J. Lutz, Anal. Chem. 41 (1969) 425.

6. Anonymous, Handbook on photonuclear data for applications, Cross sections and spectra, IAEA-TECDOC-Draft 3, March (2000).

7. H.V. Piltingsrud, Med. Phys. 9 (1982) 514.

8. V.F. Gerasimov, et al., Voprosy Atomnij Nauki i Techniki 4 (1985) 57.

9. Anonymous, Charge particle cross-section database for medical radioisotope production: diagnostic radioisotopes and monitor reactions, IAEA-TECDOC 1211, May (2001).

10. Anonymous, International Journal of High-Energy Physics, January 27, CERN Courier (2009).

11. T. Ruth, Nature 457 (2009) 536.

12. http://admin.triumf.ca/facility/5yp/comm/ isotope-task-force.php (2009).

13. Anonymous, Accelerator in Medical Isotopes Production, International Science and Technology Center, Project \#A-1444 (2009).

14. J.N. Bradbury, E.A. Knapp and D.E. Nagle, IEEE Trans. Nucl. Sci. NS-22 (1975) 1755.

15. R.W. Hann, Compact Ion Linacs for Radionuclide Production, AccSys Technology Inc. (1989).

16. Anonymous, Cyclotron Produced Radionuclides: Principles and Practice, IAEA Tech. Rep. Series 465 (2008). 